Измерены показатели:

$\mathrm{VO}_{2}=0,2283$ л/мнн - потребленне кислорода, газа

$\mathrm{VCO}_{2}=R Q \cdot \mathrm{VO}_{2}=0.1712 \mathrm{\pi} / \mathrm{MHн}-$ выделенне углекнслого

$\mathrm{N}_{2}=0,0105 \mathrm{r} / \mathrm{Mин}$ - экскреция азота с мочой

Скорости окнслення энергосубстратов по формулам

(8), (9)

$G=4,397 \cdot 0,1712-3,058 \cdot 0,2283-3,012 \cdot 0,0105=0,02283 \mathrm{r} / \mathrm{мин,}$

$L=1,634 \cdot(0,2283-0.17 ! 2)-1,94 ! \cdot 0,0105=0,07282$ г $/$ мин,

$P=6,25 \cdot 0.0105=0,0659 \mathrm{r} / \mathrm{Mнн}$.

Скорости энергопродукции по формулам (10) - (13)

$Q_{G}=3,81 \cdot 0,02283=0,08698$ ккал $/$ мин $=125,2512$ ккал $/$ сут,

$Q_{L}=9,13 \cdot 0.07282=0,6648$ ккал $/$ мин $=957.312$ ккал $/$ сут

$Q_{p}=4,1 \cdot 0,0659=0,2702$ ккал $/$ мин $=389,088$ ккал $/$ сут,

$Q=0,08698+0,6648+0,2702=1,0220$ ккал $/$ мнн $=1472$ ккал $/$ сут. (16)

Процент окнсления энергосубстратов по формулам (14)-

$6 \%=(0,08698 / 1,0220) \cdot 100=8,5$,

$L \%=(0,6648 / 1,0220) \cdot 100=65,1$

$P \%=(0,2702 / 1,0220) \cdot 100=26,4$.

Эффективность энергообмена по производству полезной энергин по формулам $(17)-(21)$ :

$W_{G}=1,458 \cdot 0,02283=0,03328$ ккал $/$ мин $=47.9232$ ккал $/$ сут,

$W_{L}=3,729 \cdot 0,07282=0,2715$ ккал $/$ мнн $=390,96$ ккал $/$ сут,

$W_{p}=1,447 \cdot 0,0659=0,09536$ ккал $/$ мин $=137,3184$ ккал $/$ сут,

$W=0,03328+0,2715+0,09536=0,4001$ ккал $/$ мнн $=$

$=576.144$ ккал/сут.

$K=(0,4001 / 1,0220) \cdot 100=39 \%$

Эффективность энергообмена по потреблению кислорода по формулам (22) - (25):

$X_{Y}=0,283 \cdot 0,02283=0,00646 \pi / \mathrm{Mин}=6,46 \mathrm{mл} / \mathrm{мнн}$,

$X_{L}=0,823 \cdot 0,07282=0,05993 \mathrm{r} / \mathrm{мнн}=59,93 \mathrm{мл} / \mathrm{мнн}$

$X_{p}=0,344 \cdot 0,0659=0,02267 \pi / \mathrm{мин}=22,67 \mathrm{мл} /$ мин.

$X=0,00646+0,05993+0,02267=0,08906 \Omega / м н н=89,06 \mathrm{мл} /$ мин

\section{Выв оды}

1. Метод непрямой калориметрии при ИНЗСД тучных позволяет получить снстемное представление об обмене белков, жиров и углеводов.

2. Включение в диету больных ИНЗСД тучных растительного белка (от 30 до $60 \%$ ) сопровождается существенным изменением энергообмена покоя за счет повышения окисления углеводов и снижения катаболизма белков, что можно расценивать как благоприятный фактор.

3. У больных ИНЗСД близкое к максимальному положительное влияние на энергообмен достигается при I стелени ожирения на фоне $30 \%$ соевой диеты, а при II степени ожирения - на фоне $45 \%$ соевой диеты.

\section{ЛИТЕРАТУРА}

1. Афифи А., Эйзен С. Статнстический анализ. Подход с нспользованием ЭВМ.-- М., 1982

2. Дедов И. И., Древаль А. В., Тищин Д. П. // Сов. мед.1987. - № 5.- С. $12-15$.

3. Яцышина Т. А., Мецерякова В. А., Плотникова О. А. и др.// Вопр. питания.-1986.- № 5.-С. 13-17.

4. Volgarev M., Vysotsky V., Jatsyshina T., Meshcheryakova V. / New Protein Foods in Human Health / Eds F. Steinke et al.- London, 1992 - Chapt. 17.- P. 161-173.

Поступнл 28.0592

A. V. Dreval, V. G. Vysotsky, T. A. Yatsyshina, O. A. Plotnikova, D. P. Tishin, N. V. Anykina, O. I. Chernyak - INDIRECT CALORIMETRY IN THE DIFFERENTIAL DIAGNOSIS OF THE METABOLIC STATUS OF OBESE PATIENTS WITH NON-INSULIN DEPENDENT DIABETES MELLITUS

Summary. Twenty-one obese patients with non-insulin dependent diabetes mellitus, 16 female and 5 male ones, were fed similar isocaloric rations, differing only by the share of sub. stitution of the traditional protein products $(0 \% .60 \%, 30 \%$. $45 \%$ ) in the Danpro-S, Danpro-Fibre soybean protein concentrate. The parameters tested were daily glycemia, C-peptides, blood hydrocortisone, and urinary excretion of nitrous metabolites. Indirect calorimetry was used to assess the protein, fat, and carbohydrate oxidation rates at rest. Addition of proteins of a plant origin to the diets of such patients was associated witg significant changes of the energy metabolism at rest at the expense of increased oxidation of carbohydrates and reduced protein catabolism, that may be regarded as a favorable effect. In this patient population a $30 \%$ soybean diet brings about an almost maximal posilive effect in patients with the first degree of obesity, whereas in those with the second degree of obesity such effect is attained by the $45 \%$ soybean diel.

(C) КОЛЛЕКТНВ АВТОРОВ, 1993

уДК 616.379-008.64-085.31:547.495.2|-056.8-07

И. М. Кахновский, Т. В. Королева, В. Н. Захарченко, С. Н. Ларионов

СРАВНИТЕЛЬНАЯ ОЦЕНКА ВЛИЯНИЯ ГЛЮРЕНОРМА И НЕКОТОРЫХ ПРЕПАРАТОВ СУЛЬФОНИЛМОЧЕВИНЫ НА ПОКАЗАТЕЛИ ВНУТРИСОСУДИСТОЙ МИКРОЦИРКУЛЯЩИИ ПРИ САХАРНОМ ДИАБЕТЕ II ТИПА

Кафедра внутренних болезней № 1 (зав. И. М. Кахновский)

Московской медицннской академин им. Н. М. Сеченова

За последние годы возможности гипогликемизирующей терапии сахарного днабета (СД) II типа значительно расширились благодаря появлению ряда новых преларатов сульфоннлмочевины, одним нз которых является глюренорм (гликвидон) фирмы «Boehringer Ingelheim», ФРГ. Особенностью глюренорма по сравнению с другими препаратами этой группы является его выделенне из организма, в основном через желудочно-кишечный тракт, что позволяет использовать его в лечении больных СД с поражением почек. Кроме того, глюренорм можно условно отнести к препаратам сульфонилмочевины «короткого» действия, длительность активного терапевтического эффекта которого не превышает $6-8$ ч.
В большинстве проведенных ранее исследований сравнительное изучение особенностей сахаропонижающнх препаратов связано с ощенкой нх гипогликемнзирующего действия. Однако наряду с этим в последнее время значнтельный интерес стали проявлять $\mathrm{k}$ изучению влияния этих лекарственных форм на состояние микроциркуляции.

Проблема микрососудистых нарушений н лечения прн СД является одной из наиболее актуальных в диабетологии. Известно, что некоторые сахаропонижающие препараты положительно влияют на микроциркуляцию: они уменьшают адгезивно-агрегационные свойства тромбоцитов, повышают фибрннолитическую активность и способствуют стабилизации, а нногда и регрессии 

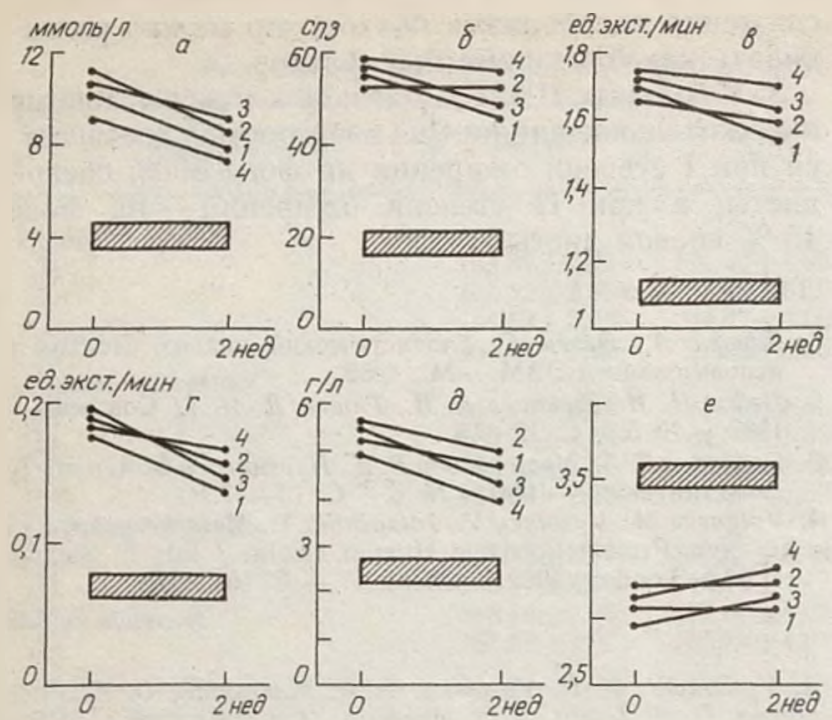

Рис. 1. Динамика некоторых микроцнркуляторных показателей и уровня гликемии у больных СД 1-4-й груплы до н после первоначальной (2 нед) коррекции суточной дозы преларатов сульфонилмочевины, предпрннятой для достижения комленсации углеводного обмена.

a- глюкоза кронн, 6 - вязкость крпвн, а- агрегачия зритроцнтон, $\boldsymbol{z}$ - агре гация тромбоцнтов, $d-$ фибрнноген, $e-$ фнбринолитическая акти нность. 3 десь н на рнс 2: цнфры ирн кривых - группа больных. Заштрнхованные прямоугольники - норма

атеросклеротического поражения сосудистой стенки [1. 3]. Однако большинство исследователей объясняют отмеченный эффект как опосредованный и связывают его с улучшением контроля гликемии [2]. Поскольку сахаропонижающая терапия при СД применяется пожизненно, то проведение сравнительного анализа результатов воздействия различных препаратов сульфонилмочевины на показатели внутрисосуднстой микроциркуляции представляется вполне актуальным. В то же время работ посвященных сравнительной оценке влияния глюренорма и некоторых других пероральных гипогликемизирующих препаратов на внутрисосуднстые параметры микроциркуляции, ранее не проводилось, что послужило основанием для настоящего исследования.

\section{Материалы и методы}

Обследовано 172 больных СД ІІ типа среднетяжелой формы с длительностью заболевания от 3 до 19 лет и различной стеленью выраженности диабетических микроангиопатий. Возраст больных колебался от 38 до 76 лет Мужчин было 69 женцин - 103. у 58 больных отмечалась нзбыточная масса тела. Для проведения сравнительного анализа результатов обследования все больные были разделены на 4 группы, адекватные по основным клиническим признакам. Больные 1-й группы $(n=57)$ получали глюренорм (гликвидон) в суточной дозе от 15 до 90 мг, больные 2 -й группы $(n=63)$ - препараты глибенкламнда (манинил, глинил, бетаназе) в суточной дозе от 5 до 15 мг, больные 3 -й груплы $(n=43)$ - глипизид (минидиаб) в суточной дозе от 2,5 до $20 \mathrm{mr}$, больные 4 -й групиы $(n=9)$ - хлорпропамид (диабннезе) в суточной дозе от 500 до 750 мг. В первые 2-е недели указанного лечения подбирали адекватную дозу сахарогонижающнх препаратов для достижения компенсация углеводного обмена, затем через 3-4 мес обследовали на фоне проводимой терапии. Контрольную группу составили 19 ирактически здоровых людей.

Состояние внутрисосуднстой мнкроциркулящии оценнвали по показателям агрегации тромбоцитов и эритроцитов (методом Born и О'Brien в модификации В. А. Люсова и соавт.) вязкости крови (на ротационном внскозиметре конструкции В. Н. Захарченко и соавт.), концентрации фибриногена (по
Рутбергу) и уровню фибрннолитнческой активности (по Коваржнку н Вулку).

\section{Результаты и их обсуждение}

Во всех группах больных СД ІІ типа, получавших различные препараты сульфонилмочевины и отобранных для сравнительного исследования, до начала наблюдения имелись достоверно выраженные, по сравнению с контролем, нарушения внутрисосудистой микроциркуляции. Как видно на рис. I, исходные показатели вязкости крови, агрегации эритроцитов и тромбоцитов, свертывания крови и фнбринолиза, а также гликемни у больных СД значнтельно превышали норму. Следует отметить, что не всегда выраженные нарушения углеводного обмена соответствовали максимальным отклонениям от контрольных показателей внутрисосудистой микроциркуляцин. Так, несмот. ря на нанменьший исходный уровень гликемии у больных, получавших хлорпропамид, показатели вязкости крови и агрегации эритроцитов у них имели наибольшие отклонения от показателей нормы. В то же время максимальные нсходные нарушения метаболнзма углеводов у больных 3-й группы, получавших глипизид, не сопровождались значительнымн изменениями большинства показателей внутрисосудистой микроциркуляции. Полученные нами данные свидетельствуют о том, что не все нарушения во внутримикроциркуляторном русле прямо и однозначно зависят от степени компенсации углеводного обмена. По-видимому, такая взаимосвязь имеет сложный, во мно гом до конца не изученный характер. Поэтому для адекватности проводимого сравнения в течение первых 2 нед наблюдения нами производилась коррекция суточной дозы применяемых препаратов сульфонилмочевины с целью относительного выравнивания уровня гликемии во всех изучаемых группах больных СД до стадии компенсации и/или субкомпенсации углеводного обмена (глюкоза кровн $<10$ ммоль/л)

Как видно на рис. 2, несмотря на отсутствие достоверных различий $(p>0,05)$ среднестатистических значений гликемии между группами больных после проведенной нами предварительной коррекции дозы препаратов, сохранялась тенденция к более низкому уровню глюкозы у больных, получавших глюренорм и хлорпропамид (I-я н 4-я группы), и к более высокому уровню глюкозы у больных, принимавших глипизнд. Прн этом показатели внутрисосудистой микроциркуляцин изменялись на фоне сравнительной терапии поразному. Так, вязкость крови и агрегация эритроцитов у больных 4-й группы практически не нмели достоверной динамики и оставались наиболее высокими. У больных, получавших глюренорм (1-я группа), достоверно снизилось большинство изучаемых параметров - вязкость крови, агрегация эритроцитов и тромбоцитов, свертывание крови. У больных 2-й и 3-й групп улучшились показатели вязкости и свертывания крови, а также акти. визировался фибринолиз. В целом после 3-4-месячного срока лечения различными препаратами сульфоннлмочевнны нанболее благопрнятное влияние на состояние клеточного звена микроциркуляции оказывали глюренорм и глипизнд. При этом по абсолютной величине изучаемых параметров наиболее эффективным в наших исследова- 

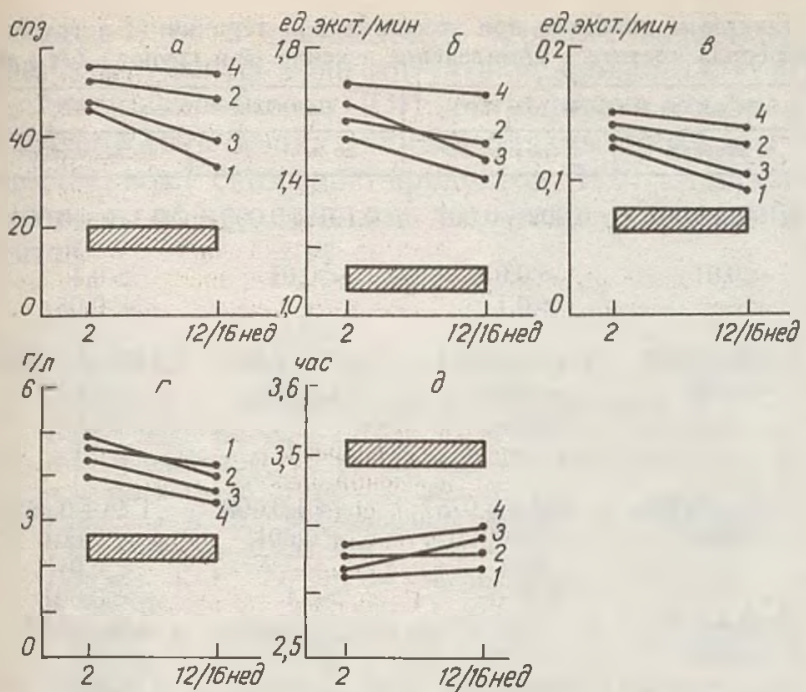

Рис. 2. Динамика некоторых микроци ркуляторных показателей у больных СД (стадия компенсацин) в зависимости от лечения различными препаратами сульфонилмочевнны (после 3-4 мес наблюдення)

a- вязкость кровн, 6 - агрегация зритрсцнтов, А- агрегация тромбонитов г-фнбриноген, д- фнбрннолитическая актнвность.

ниях оказался глюренорм. Плазменные мнкроциркуляторные факторы - фибриноген и фибри нолитическая активность после терапии претерпе вали одинаково положительную динамику у больных 2-й и 3-й групп, в наибольшей степени у лиц, получавших хлорпропамид. Сравнительный анализ полученных нами данных свидетельствует о том, что на фоне стабильной компенсации СД некоторые сахаропонижающие средства могут оказывать положительное влияние на состояние внутрисосудистой микроциркуляции, однако разные препараты воздействуют на микрососудистые изменения различно. Қак видно на рис. 2, глюренорм и глипизид в большей степени влияют на функциональную активность клеток крови по сравнению с хлорпропамидом и глибенкламидом, в то время как глибенкламид, по абсолютным показателям, больше других препаратов способен активизировать фибринолиз.

Таким образом, разлнчные препараты сульфонилмочевины по-разному влияют на внутрисосудистую микроциркуляцию при лечении больных СД II типа с компенсацией углеводного обмена. Близкими по выраженности микрососудистого эффекта являются глюренорм и глилизид. Несколь ко уступают им глибенкламид и хлорпропамид. При этом нанболее быстро микроваскулярное действие проявляется при использовании глюренорма, что делает его наиболее предпочтительным в лечении больных СД, особенно с пренмущественным нарушением клеточного звена микроциркуляцин.

\section{В ы в оды}

1. У больных СД ІІ типа имеют место достоверные нарушения мнкроциркуляции по сравнению со здоровыми людьми.

2. При достижении суб- и компенсации углеводного обмена на фоне прнменения препаратов сульфонилмочевины (глюренорм, глибенкламнд, глипизид и хлорпропамид) происходит достоверное улучшение показателей микроциркуляторного кровотока.

3. Выявлены различия в степени выраженности и точках приложення микрососудистого эффекта у разных препаратов сульфонилмочевины. Наиболее быстро и с наибольшей степенью достовер ности улучшение показателей вязкости крови, агрегации эритроцитов и тромбоцитов у больных СД II типа среднетяжелой формы наступает при применении глюренорма по сравнению с глипизндом, глибенкламидом и хлорпропамидом.

\section{ЛИТЕРАТУ РА}

1. Qram J., Jespersen J., Kold A. // Metabolism.- 1988.Vol. 37. N 10- P. 937-943

2. Melander A. // Baillier's clin. Endocr. Metab.- 1988.Vol. 2, N 2.- P. 443-453.

3. Stolar M. W. // Metabolism. - 1988-Vol. 37, Suppl. I.P. $1-9$.

Поступнла 19.11 .92

I. M. Kakhanousky. T. V. Koroleva, V. N. Zakharchenko, S. $N$. Larionov - COMPARATIVE ASSESSMENT OF THE EFFECTS OF GLURENORM AND SOME SULFONYLUREA PREPARATIONS ON MICROCIRCULATION IN TYPE II DIABETES MELLITUS

Sum m a ry. Analysis of the effects of glurenorm and some sulfonylurea drugs, such as maninil, minidiab, chlorpropamid, on some parameters of intravascular microcirculation has demonstrated the specific features of this drug. Though all these hypoglycemic agents favorably influence the microcirculation when carbohydrate metabolism compensation is attained, glurenorm improved the status of formed elements of the blood (red cell and platelet aggregation) more noticeably than the rest drugs, which fact recommends it as a drug of choice for patients with type II medium-severe diabetes with the predominant involvement of the cellular component of the microcirculation.

\section{О ПРИМЕНЕНИИ АНТИОКСИДАНТОВ ( $\alpha$-ТОКОФЕРОЛА АЦЕТАТА) В ЛЕЧЕНИИ САХАРНОГО ДИАБЕТА}

Қафедра госпитальной терапии № 2 (зав.-доктор мед. наук Н. С. Кузнецов) Крымского меднцинского института, Симферополь

Исследованиями последних лет доказана активация перекисного окисления липидов (ПОЛ) при сахарном диабете $[4-6,11]$. На фоне снижения уровня антиоксидантов $[1,2,9]$ активация ПОЛ может приводить к нарушению структуры и функцин биологических мембран $[7,11]$ и в свою 